of political, economic, social and technological factors that influence convergence and innovation. He identifies a number of conditions that need to be present in order to foster innovation, including physical and human infrastructure with emphasis on high levels of journalism education and professionalism; with links to education/training and ICT; good broadband infrastructure; freedom of expression; and liberalising laws that allow media growth.

Korea is given as a good example of ICT becoming part of mainstream education and thus building the capacity of both journalists and audiences to use new technologies. Hong Kong is used to illustrate the benefits of a liberal market environment and a good technological infrastructure: PCCW, the region's biggest telecoms company, has merged all its media assets under one platform.

But one of the biggest developments in the region's media is the growth of audience-generated content (a good example is Stomp, the Singapore Straight Times online mobile and print site with audiencegenerated content, attracting 300,000 unique visitors a month). Asia's fastgrowing mobile phone market has the potential of turning societies into a huge newsgathering force. Many media groups have also developed innovative in-house technologies for delivering breaking news. The Inquirer.net in the Philippines for instance has the most innovative website in the region through its use of multimedia. Reporters file breaking news as text messages with their blackberry mobile phones into Inquirer.net's own content management system which distributes news alerts for mobile phones. Meanwhile traditional print newspaper business is booming in India and China. Some Indian newspapers like the Hindustan Times are hotbeds of innovation, embracing integration with new technologies: 'The future is bright for Asian media companies that embrace technology and innovation, in a region whose future is promising if a little unclear' (p.167).

\section{The case for crisis communication}

The Handbook of Crisis Communication, edited by W. Timothy Coombs and Sherry J. Holladay. London, Blackwell Publishing, 2010, 737pp. ISBN 978-1-40519441-9

HIS HANDBOOK presents a
timely contribution to the growing body of literature on crisis communication. Premised on the belief that the study of crisis communication deserves recognition as a discipline distinct from public relations 
and corporate communications, this text serves as an early assertion of independence.

In keeping with the standard format of such handbooks, editors Coombs and Holladay have assembled a hefty (in every sense of the word) collection of research, theory, analysis and commentary from a range of crisis communication experts. Accordingly, the book provides a comprehensive, state-ofthe-art review that will likely prove an invaluable resource for both academics and practitioners working in the field. Journalists and journalism educators alike will further appreciate the common focus on issues of news coverage, media representation and the framing of crisis and associated conflict.

In the introduction, Part I establishes the scope of the field, provides a comprehensive review of the extant literature, and explicates the connections between crisis communication and related fields-specifically, issues management, risk management, disaster communication, and reputation management. Comprising three chapters, this section illuminates the trends and shifts in crisis communication research, culminating with a meta-analysis of relevant research published in the Journal of Public Relations Research and Public
Relations Review from 1975-2006. In the latter, as in the majority of contributions throughout the book, the dominance of public relations as a parental discipline is still most apparent.

Scholars of crisis will appreciate the methodological diversity represented in Part II. The editors have clearly attempted to counter the prevalence of case-study research in the discipline with the inclusion of a number of studies illustrating the utility of alternative approaches such as textual and content analysis, and experimental methods. The readings here explore the communicative response and media coverage of such public events as Hurricane Katrina and the Virginia Tech Shootings.

Parts III and IV centre on the practice of crisis communication and its application in organisational contexts respectively, while Part V explores the use of technology and media in crisis communication. Part VI presents a commendable attempt to situate crisis communication on a global level whereas Part VII, the largest section, emphasises theoretical developments in the field. The final section, Part VIII, offers commentary on future directions for crisis communication research.

The book is not without its limitations. Perhaps unavoidably at this 
stage in the development of the (sub) discipline and given the nature of the topic, the book is heavily reliant on case-based analyses. These inclusions frequently make for engaging reading (the JetBlue Airways crisis by Gregory Efthimiou and the Danish news 'cartoon affair' by Frandsen and Johansen are standouts in this respect), yet they exemplify a common shortcoming in the crisis communication literature as identified by contributor Michael Kent. Specifically, Kent observes 'the many crisis critiques that have been conducted [will] remain mere anecdotes, instructive but not predictive' (p. 710).

The heuristic value of The Handbook of Crisis Communication is however undeniable. The volume serves to establish crisis communication as a visible and vibrant area of research. Whether it has yet achieved emancipation as a field remains debatable but the Handbook clearly presents a sound opening argument. - Donna Henson, Assistant Professor at Bond University.

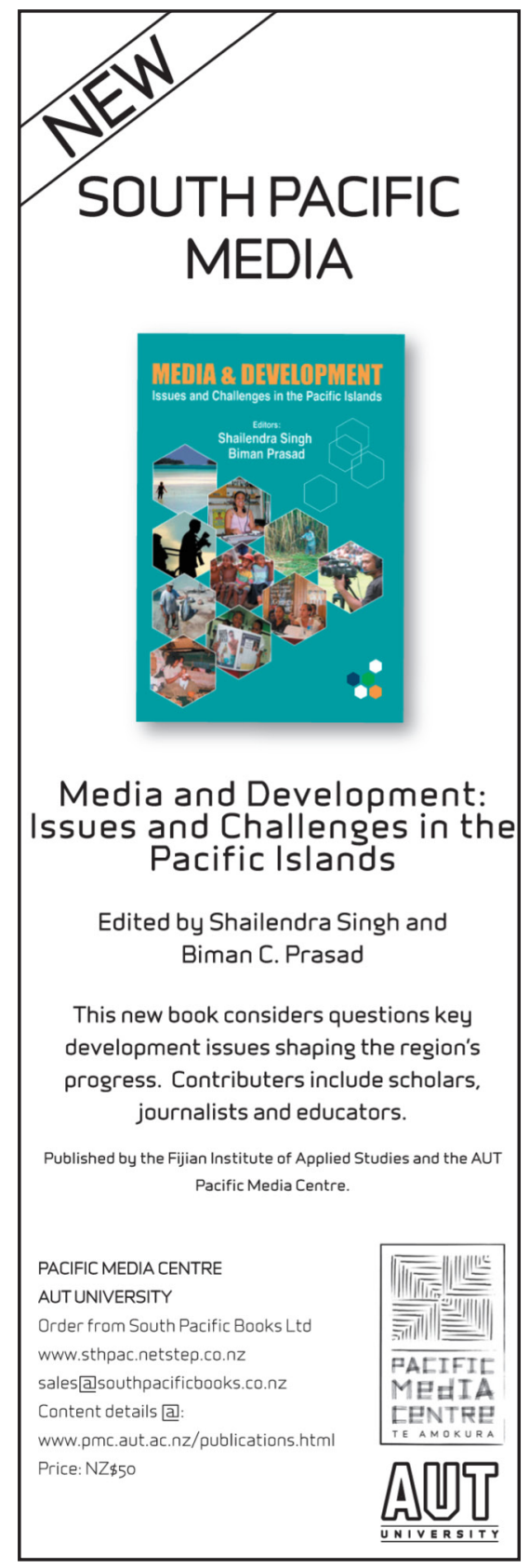

